
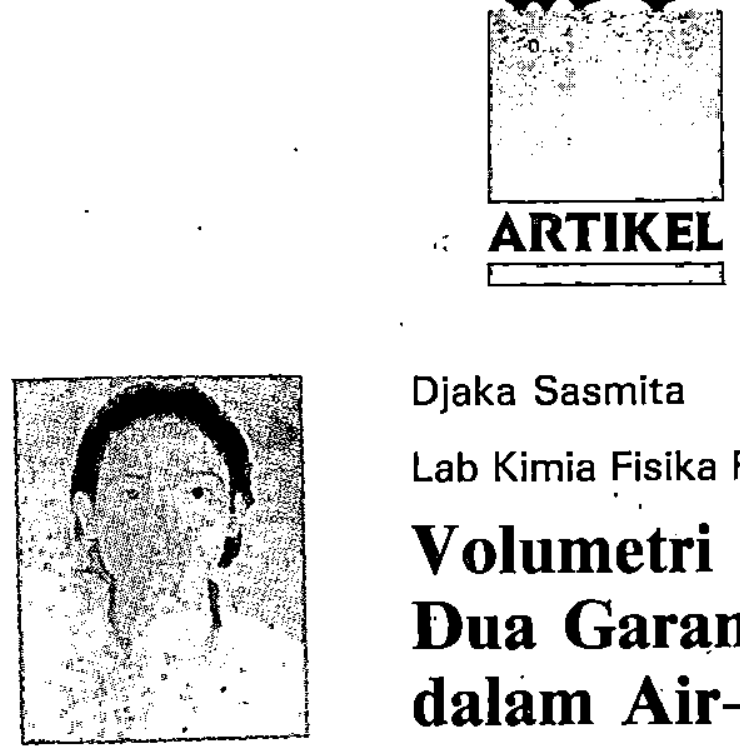

\title{
Djaka Sasmita
}

\section{Lab Kimia Fisika FMIPA UGM Yogyakarta} Volumetri Larutan Dua Garam Halida dalam Air-Dioksän

\section{Sari}

Telah dilakukan perhitungan volum molar semu pada konsentrasi zarut secara limit mendekati nol dari data rapat massa dan konsentrasi. Sistem yang diteliti adalah larutan dua garam dalam pelarut air-dioksan $10 \%$ massa. Perhitungan dilaksanakan menggunakan dua metoda yaitu molaritas (cara I) dan molalitas (cara II) pada variasi suhu.

Cara I dan II secara praktis memiliki kelinearan yang sama untuk plot volum molar semu lawan akar konsentrasi (perbedaan $\mathrm{S}_{\mathrm{e}}$ adalah antara 0,6-1,6\%). Cara I dan II secara praktis memberikan volum molar

semu $V_{S}^{O}$ yang sama. Volum molar semu vo untuk $\mathrm{CdC12}$ (A) adalah menurun dengan kenaikan suhu, sedangkan volum molar semu $v_{S}^{\text {O }}$ untuk CdI2 (B) adalah naik dengan kenaikan suhu, dan pada suhu. $303 \mathrm{~K}$ bernilai negatif.

\section{Pendahuluan}

Kajian volumetrik telah banyak dilakukan pada larutan eletrolit tunggal, tetapi belum banyak dilakukan terhadap larutan campuran elektrolit. Kajian campuran dua garam kadmium halida dalam pelarut air-dioksan $10 \%$ massa telah dilakukan oleh Blokhra dan Agarwal (1978) dengan tujuan antara lain untuk mendapatkan informasi tentang interaksi zarut-pelarut dalam larutan elektrolit multikomponen.

Grafik volum molar semu lawan akar konsentrasi biasanya memberikan garis lurus dan intersepnya adalah limit volum molar semu pada konsentrasi sama dengan nol $v_{S}^{O}$ yang diperlukan untuk menentukan volum molar parsial komponen pada berbagai konsentrasi. Penentuan intersep grafik adalah lebih mudah dilakukan pada grafik linear daripada pada. grafik lengkung. Untuk mendapatkan kelinearan pada relasi tersebut sebagian ahli memilih mola- 
litas dan sebagian yang lain memilih molaritas sebagai satuan konsentrasi. Blokhra dan Agarwal (1978) telah menggunakan molaritas untuk menentukan $v_{S}^{o}$, sedangkan Lewis dan Randall (1961) menganjurkan penggunaan molalitas. Mengingat kelinearan relasi itu akan digunakan pada perhitungan volumetrik selanjutnya, maka pemilihan metoda analisa data yang memberikan kelinearan lebih tinggi adalah penting untuk dilakukan. Pada makalah ini akan dibandingkan kelinearan relasi menggunakan molaritas sebagai satuan konsentrasi dengan kelinearan menggunakan molalitas sebagai kesatuan konsentrasi. Intersep grafik yang menurut Blokhra dan Agarwal dapat digunakan untuk menerangkan interaksi antara molekul pelarut dan molekul zarut juga akan dihitung dan dibandingkan pada penggunaan molalitas dan pada penggunaan molaritas.

Informasi tentang volum molar parsial komponen di dalam larutan adalah perlu. Ini antara lain digunakan untuk melihat pengaruh tekanan sistem terhadap potensial kimia, sedangkan untuk melihat pengaruh tekanan terhadap entropi komponen diperlukan adanya variasi suhu. Dengan alasan ini maka perhitungan volum molar pada variasi suhu juga perlu dilaporkan.

\section{Teori}

Volum molar parsial komponen i ditakrifkan sebagai

$v_{i}=\left(\partial V / \delta n_{i}\right)_{T, p, n j} \neq i$

yaitu turunan volum larutan $\mathrm{v}$ terhadap jumlah mol komponen i pada kondisi suhu $T$, tekanan $p$ dan jumlah mol komponen $\mathrm{j}$ yang bukan $\mathrm{i}$ yang dijaga tetap. Takrif ini menunjukkan bahwa volum molar parsial adalah suatu hasil diferensial secara parsial.

Jika volum larutan $\mathrm{V}$ dipandang sebagai besaran yang merupakan fungsi suhu, tekanan dan jumlah mol komponen-komponen larutan, maka $\cdot \mathrm{V}=\mathrm{V}\left(\mathrm{T}, \mathrm{p}, \mathrm{n}_{\mathrm{j}}\right)$

yang pada suhu dan tekanan tetap $\mathrm{V}=\mathrm{V}\left(\mathrm{n}_{\mathbf{i}}\right)$

sehingga pada kondisi ini diferensialnya dapat dinyatakan sebagai

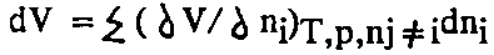

Persamaan (1) dan (2) memberikan $\mathrm{dV}=\Sigma \mathrm{v}_{\mathrm{i}} \mathrm{dn_{ \textrm {i } }}$

Penyelesaian persamaan (3) memberikan

$\mathrm{V}=\boldsymbol{\Sigma} \mathrm{n}_{\mathrm{i}} \mathbf{v}_{\mathbf{i}}$

Volum molar parsial semu $\mathrm{v}_{\mathrm{s}}$ ditakrifkan memenuhi hubungan yang semacam dengan hubungan $\mathrm{V}=\mathrm{n}_{1} \mathrm{v}_{1}+\mathrm{n}_{2} \mathrm{v}_{2}$ dengan subskrip 1 dan 2 menyatakan pelarut dan zarut, yaitu

$\mathrm{v}=\mathrm{n}_{1} \mathrm{v} \mathrm{P}+\mathrm{n}_{2} \mathrm{v}_{\mathrm{s}}$.

Terlihat bahwa persamaan yang akhir diperoleh dari persamaan semula dengan menggantikan volum molar parsial $\mathrm{v}_{1}$ dengan volum molar parsial pada keadaan konsentrasi zarut sama dengan nol yaitu $\mathrm{v}_{1}{ }^{0}$. Persamaan yang akhir memberikan pernyataan eksplisit volum molar semu sebagai

$\mathrm{v}_{\mathrm{s}}=1 / \mathrm{n}_{2}\left(\mathrm{~V}-\mathrm{n}_{1} \mathrm{v} \rho\right)$

Hubungan ini tidak terbatas hanya pada sistem yang terdiri atas dua 
komponen, tetapi dapat juga digunakan untuk sistem yang terdiri atas lebih dari dua komponen. Ini dapat dilakukan dengan memandang sistem itu sebagai dua komponen, yaitu subskrip 2 diperlakukan untuk zat yang akan ditentukan volum molar semuanya dan subskrip 1 diperlukan untuk komponen-komponen laininya dalam sistem tersebut.

Untuk menentukan volum molar semu suatu komponen dalam larutan sebagai fungsi konsentrasinya, maka dapat digunakan prosedur berikut :

Volum molar semu dipandang merupakan fungsi linear dari akar konsentrasi, $v_{s}=v_{S}^{0}+B \sqrt{C}$, dengan $B$ adalah tetapan dan $C$ adalah konsentrasi komponen. Dari data volum molar semu dan konsentrasi komponen pada konsentrasi-konsentrasi yang dicoba dalam eksperimen, dapat dibuat grafik volum molar semu lawan akar konsentrasi yang memberikan

lurus dengan intersep $v_{S}^{O}$ dan lereng B. Dàri kedua nilai ini volum molar semu pada berbagai konsentrasi di sekitar konsentrasi-konsentrasi yang dicoba dapat dihitung.

Satuan konsentrasi yang digunakan untuk membuat grafik volum molar semu lawan akar konsentrasi sering dinyatakan dalam molaritas (Blokhra dan Agarwal, 1978) dan sering pula dalam molalitas (Lewis dan Randall, 1961; Castellan, 1975). Perbedaan sistem satuan konsentrasi yang digunakan secara nalar akan memberikan perbedaan tingkat kelinearan. Dalam makalah ini, intersep dan kelinearan kedua cara tersebut akan ditentukan, untuk memilih prosedur yang lebih baik.

Tingkat kelinearan grafik y lawan $x$ yang pernyataan regrasi linearnya adalah $\hat{y}_{i}=a+b x_{i}$, pada titik-titik eksperimen $\left(\mathrm{x}_{\mathrm{i}}, \mathrm{y}_{\mathrm{i}}\right)$ diukur dari nilai salah estimasi $\mathrm{S}_{\mathrm{e}}$ yang ditakrifkan sebagai

$\mathrm{S}_{\mathrm{e}}=V\left(\mathrm{E}\left(\mathrm{y}_{\mathrm{i}}-\hat{\mathrm{y}}_{\mathrm{i}}\right)^{2} /(\mathrm{n}-2)\right)$

dengan $n$ adalah jumlah data eksperimen. Nilai $y_{i}-y_{i}$ menyatakan selisih y eksperimen dengan y yang dihitung dari persamaan regresi linear. Jika hubungan itu linear sempurna yang berarti bahwa semua titik eksperimen terletak pada grafik, maka $\mathrm{y}_{\mathrm{i}}=\hat{y}_{\mathrm{i}}$ untuk semua $\mathrm{i}$ dan ini mengakibatkan selisih tersebut sama dengan nol sehingga Se pada (6) juga bernilai nol. Menurut persamaan (6) maka Se tidak pernah negatif dan paling kecil bernilai nol. Untuk jumlah data $\mathrm{n}$ dan $y_{i}$ yang sama, maka perbedaan $x_{i}$ (misalnya karena perbedaan satuan yang digunakan seperti molaritas dan molalitas) yang dapat memberikan perbedaan pernyataan regresi linear $\hat{y}_{\mathrm{i}}=\mathrm{a}+\mathrm{bx}_{\mathrm{i}}$ akan dapat memberikan perbedaan Se. Semakin besar Se maka pembilang di dalam akar pada ruas kanan harus semakin besar sehingga selisih $y_{i}$ dan $\hat{y_{i}}$ juga semakin besar atau $y_{i}$ makin jauh dari $\hat{y}_{j}$. Kondisi ini adalah kondisi hubungan yang linearitasnya semakin rendah. Jadi jika Se makin tinggi maka dengan kendala yang diberikan tersebut, tingkat kelinearan menjadi semakin kecil.

\section{Hasil dan Pembahasan}

Data yang didapatkan oleh Blokhra 
dan Agarwal (1978) adalah seperti dinyatakan pada tabel 1 dan 2 . Tabel 1 menyatakan volum molar semu pada sistem campuran garam $\mathrm{CdCl} 2$ dan CdI2 dalam pelarut air-dioksan dengan konsentrasi CdI2 $\mathrm{C}_{\mathrm{B}}$ tetap $=$ $0.05 \mathrm{~mol} / \mathrm{dm}^{3}$ sedangkan konsentrasi $\mathrm{CdCl} 2 \mathrm{C}_{\mathrm{A}}$ bervariasi untuk tiga variasi suhu yaitu 30,308 dan $313 \mathrm{~K}$. Tabel 2 menyatakan volum pelarut yang sama dengan konsentrasi $\mathrm{CdCl} 2 \mathrm{C}_{\mathrm{A}}$ tetap $=0.05 \mathrm{~mol} / \mathrm{dm}^{3}$ sedangkan konsentrasi $\mathrm{CdI} 2 \mathrm{C}_{\mathrm{B}}$ bervariasi untuk variasi suhu yang sama dengan tabel 1 .
$1000 \mathrm{C}_{\mathrm{A}} /\left(1000 \mathrm{~d}-\mathrm{C}_{\mathrm{A}} \mathrm{M}_{\mathrm{A}}-\mathrm{C}_{\mathrm{B}} \mathrm{M}_{\mathrm{B}}\right)$. Rumus ini menunjukkan adanya pengaruh rapat massá larutan d terhadap molalitas. Karenā rapat massa larutan adalah gayut suhu, maka molalitas menjadi gayut suhu.

Dari tabel. 2 molaritas komponen molalitas menjadi gayut suhu. Dari tabel 2 molaritas komponen GdI2 $\mathrm{C}_{\mathrm{B}}$ dapat digantikan dengan molalitasnya $\mathrm{m}_{\mathrm{B}}$ pada molaritas $\mathrm{CdCl} 2$ yang tetap $C_{A}$, sehingga diperoleh tabel 4 . Rumus yang digunakan untuk mendapatkan molalitas A dan B dari

Tabel 1 . Volum molar semu sistem campuran garam $\mathrm{CdCl} 2$ dan $\mathrm{Cd} / 2$ dalam pelarut air-dioksan pada molaritas $\mathrm{CdCl} 2 \mathrm{C}_{\mathrm{A}}$ tetap dan molaritas $\mathrm{CdI}_{2} \mathrm{C}_{\mathrm{A}}$ berubah untuk tiga macam suhu.

\begin{tabular}{|c|c|c|c|c|c|c|c|}
\hline \multirow{2}{*}{$\mathrm{C}_{\mathrm{A}} ; \mathrm{mol} / \mathrm{dm} 3$} & \multirow{2}{*}{$\begin{array}{c}\mathrm{C}_{\mathrm{B}}, \mathrm{mol} / \mathrm{dm} \mathbf{3}^{-} \\
\mathrm{T} / \mathrm{K}\end{array}$} & \multirow{2}{*}{303} & \multirow{2}{*}{$\begin{array}{c}\text { ro,g/çc } \\
308\end{array}$} & \multirow[b]{2}{*}{313} & \multirow[b]{2}{*}{303} & \multicolumn{2}{|c|}{$\mathrm{phi}, \mathrm{cc} / \mathrm{mol}$} \\
\hline & & & & & & 308 & 313 \\
\hline$\therefore \quad 0.01000$ & 0.05000 & 1.017810 & 1.015474 & 1.013281 & 60.40 & 41.13 & 7.52 \\
\hline 0.02000 & 0.05000 & 1.018842 & 1.016731 & 1.014935 & 69.70 & 48.82 & 12.56 \\
\hline 0.03000 & 0.05000 & 1.019714 & 1.017845 & 1.016538 & 78.05 & 56.32 & 15.96 \\
\hline$: 0.04000$ & $0.05000^{\circ}$ & 1.020423 & 1.018933 & 1.018045 & 86.16 & 60.56 & 20.03 \\
\hline 0.05000 & 0.05000 & $1.021092^{\circ}$ & 1.019840 & 1.019477 & 91.85 & 66.65 & 23.95 \\
\hline
\end{tabular}

Tabel 2. Volum molar semu sistem campuran garam $\mathrm{CdCl} 2$ dan $\mathrm{Cd} 22$ dalam pelarut air-dioksan pada molaritas $\mathrm{Cd} 2 \mathrm{C}_{\mathrm{B}}$ tetap dan molaritas $\mathrm{CdCl} 2 \mathrm{C}_{\mathrm{A}}$ berubah untuk tiga macam suhu.

\begin{tabular}{ccccccccc}
\hline $\mathrm{C}_{\mathrm{A}}, \mathrm{mol} / \mathrm{dm} 3$ & $\begin{array}{c}\mathrm{C}_{\mathrm{B}}, \mathrm{mol} / \mathrm{dm} 3 \\
\mathrm{~T} / \mathrm{K}\end{array}$ & 303 & 308 & 313 & 303 & 308 & 313 \\
\hline 0.05000 & 0.00000 & 1.008259 & 1.005152 & 1.003699 & & & \\
0.05000 & 0.00918 & 1.011423 & 1.008093 & 1.007023 & 21.55 & 45.81 & 57.31 \\
0.05000 & 0.01836 & 1.014231 & 1.010701 & 1.009530 & 40.58 & 63.63 & 75.36 \\
0.05000 & 0.02754 & 1.016940 & 1.013122 & 1.010962 & 50.53 & 76.37 & 90.40 \\
0.05000 & 0.03672 & 1.019491 & 1.015410 & 1.013041 & 59.82 & 86.37 & 102.46 \\
0.05000 & 0.04590 & 1.021905 & 1.017422 & 1.015102 & 68.32 & 96.40 & 110.17 \\
\hline
\end{tabular}

Dari-tabel 1 molaritas komponen $\therefore \mathrm{CdCl} 2 \mathrm{C}_{\mathrm{A}}$ dapat digantikan dengan molalitasnya $\mathrm{m}_{\mathrm{A}}$ pada molaritas $\mathrm{Cd} / 2$ yang tetap $\mathrm{C}_{\mathrm{B}}$, sehingga diperoleh tabel 3. Rumus $m_{A}=$ molaritasnya berturut-turut adalah

$$
\begin{aligned}
& \mathrm{m}_{\mathrm{A}}= \\
& 1000 \mathrm{C}_{\mathrm{A}} /\left(1000 \mathrm{~d}-\mathrm{C}_{\mathrm{A}} \hat{\mathrm{M}}_{\mathrm{A}}-\dot{\mathrm{C}}_{\mathrm{B}} \mathrm{M}_{\mathrm{B}}\right) \\
& \operatorname{dan} \mathrm{m}_{\mathrm{B}}=- \\
& 1000 \cdot \mathrm{C}_{\mathrm{B}} /\left(1000 \mathrm{~d}-\dot{\mathrm{C}}_{\mathrm{A}} \mathrm{M}_{\mathrm{A}}-\mathrm{C}_{\mathrm{B}} \mathrm{M}_{\mathrm{B}}\right) .
\end{aligned}
$$


Tabel 3. Volum molar semu sistem campuran garam $\mathrm{CdCl} 2$ dan $\mathrm{CdI} 2$ dalam pelarut air-dioksan pada molaritas $\mathrm{Cd} 12 \mathrm{C}_{\mathrm{B}}$ tetap dan molalitas $\mathrm{CdCl} 2 \mathrm{C}_{\mathrm{A}}$ berubah untuk tiga macam suhu.

\begin{tabular}{ccccccc}
\hline $\mathrm{m}_{\mathrm{A}}$, molal & & & $\mathrm{C}_{\mathrm{B}}, \mathrm{mol}$ & $/ \mathrm{dm} 3$ & $\mathrm{v}_{\mathrm{s}, \mathrm{cc}}$ & $/ \mathrm{mol}$ \\
$\mathrm{T} / \mathrm{K} \mathrm{303}$ & 308 & 313 & & 303 & 308 & 313 \\
\hline 0.01002 & 0.01005 & 0.01007 & 0.050000 & 60.40 & 41.13 & 7.52 \\
0.02006 & 0.02011 & 0.02014 & 0.050000 & 69.70 & 48.82 & 12.56 \\
0.03012 & 0.03018 & 0.03022 & 0.050000 & 78.05 & 56.32 & 15.96 \\
0.04021 & 0.04027 & 0.04031 & 0.050000 & 86.16 & 60.56 & 20.03 \\
0.05032 & 0.05038 & 0.05040 & 0.050000 & 91.85 & 66.65 & 23.95
\end{tabular}

Tabel 4. Volum molar semu sistem campuran garam $\mathrm{CdCl} 2$ dan $\mathrm{Cd} 2$ dalam pelarut air-dioksan pada molaritas $\mathrm{CdCl} 2 \mathrm{C}_{\mathrm{A}}$ tetap dan molalitas CdI2 $\mathrm{C}_{\mathrm{B}}$ berubah untuk tiga macam suhu

\begin{tabular}{ccccccc}
\hline $\begin{array}{c}\mathrm{m}_{\mathrm{B}} \text {, molal } \\
\mathrm{T} / \mathrm{K} 303\end{array}$ & \multicolumn{2}{c}{$\mathrm{C}_{\mathrm{B}}, \mathrm{mol} / \mathrm{dm} 3$} & \multicolumn{3}{c}{$\mathrm{v}_{\mathrm{s}}, \mathrm{cc} / \mathrm{mol}$} \\
& 308 & 313 & & 303 & 308 & 313 \\
\hline 0.050000 & 0.00919 & 0.00922 & 0.00923 & 21.55 & 45.81 & 57.31 \\
0.050000 & 0.01839 & 0.01846 & 0.01848 & 40.58 & 63.63 & 75.36 \\
0.050000 & 0.02760 & 0.02771 & 0.02777 & 50.53 & 76.37 & 90.40 \\
0.050000 & 0.03683 & 0.03699 & 0.03707 & 59.82 & 86.37 & 102.46 \\
0.050000 & 0.04609 & 0.04630 & 0.04640 & 68.32 & 98.40 & 110.17 \\
\hline
\end{tabular}

Keempat tabel ini memberikan volum molar semu pada limit konsentrasi nol $v_{\mathrm{S}}^{0}$ dan salah estimasi $\mathrm{S}_{\mathrm{e}}$ seperti dinyatakan pada tabel 5 .

salah estimasi atau tidak memberikan perbedaan kelinearan. Dengan cara yang sama secara praktis dapat pula dikatakan bahwa kedua cara juga

\begin{tabular}{|c|c|c|c|c|c|}
\hline & $v_{s} 0$ & $\mathrm{~S}_{\mathrm{eA}}$ & & $v_{s} 0$ & $\mathrm{~S}_{\mathrm{eB}}$ \\
\hline & $\mathbf{A}$ & & & B & \\
\hline 303 & cara I & $33,92 \pm 1,35$ & 0,76 & $-14,09 \pm 2,81$ & 1,58 \\
\hline & cara II & $34,03 \pm 1,33$ & 0,75 & $-13,97 \pm 2,83$ & 1,59 \\
\hline 308 & cara I & $20,37 \pm 1,21$ & 0,68 & $4,07 \pm 1,67$ & 0,94 \\
\hline & cara II & $20,43 \pm 1,21$ & 0,68 & $4,25 \pm 1,64$ & 0,93 \\
\hline 313 & cara I & $-5,92 \pm 1,10$ & 0,62 & $14,06 \pm 2,13$ & 1,19 \\
\hline & cara II & $-5,91 \pm 1,10$ & 0,62 & $14,30 \pm 2,15$ & 1,21 \\
\hline
\end{tabular}

Pada tabel 5 terlihat bahwa nilai salah estimasi cara I kadang-kadang lebih besar, sama, dan kadang-kadang lebih kecil dari nilai untuk cara II, dengan perbedaan yang sangat kecil yaitu antara 0,6 - 1,6\%, sehingga secara praktis dapat dikatakan bahwa kedua cara tersebut tidak memberikan beda memberikan nilai volum molar semu $v_{S}^{O}$ yang sama.

Pengaruh suhu terhadap volum molar semu dapat dinyatakan sebagai berikut :

Volum molar semu vo untuk $\mathrm{CdCl} 2$ (A) adalah menurun dengan kenaikan 
suhu, dan bahkan menjadi negatif nilainya pada suhu $313 \mathrm{~K}$. Volum molar semu vo untuk CdI2 (B) adalah naik dengan kenaikan suhu, dan pada suhu $303 \mathrm{~K}$ bernilai negatif.

\section{Kesimpulan}

1. Cara I dan II secara praktis memiliki kelinearan yang sama (perbedaan $\mathrm{S}_{\mathrm{e}}$ adalah antara $0,6-1,6$ \%).

2. Cara I dan II secara praktis memberikan volum molar semu $v_{S}^{0}$ yang sama.

3. Volum molar semu $v_{S}^{o}$ untuk $\mathrm{CdCl} 2$ (A) adalah menurun dengan kenaikan suhu, sedangkan volum molar semu vo untuk CdI2 (B) adalah naik dengan kenaikan suhu, dan pada suhu $303 \mathrm{~K}$ bernilai negatif.

\section{Daftar Pustaka}

Blokhra, R.L. and S.K. Agarwal. 1979, J. Chem. Thermodynamics 1, 229-231.

Castellan, G.W. 1975. Physical Chemistry. Addison-Wesley Publishing Company, Reading : Massachussets.

Lewis,G.N. and M.Randall. 1961. Thermodynamics. McGraw-Hill Book Company Inc. : New York. 